\title{
Aerobic, Catalytic Oxidation of Alcohols in Ionic Liquids
}

\author{
Roberto F. de Souza, ${ }^{a}$ Jairton Dupont ${ }^{a}$ and Jeane E. de L. Dullius ${ }^{*, b}$ \\ ${ }^{a}$ Instituto de Química, Universidade Federal do Rio Grande do Sul, Av. Bento Gonçalves, 9500, \\ 91501-970 Porto Alegre - RS, Brazil \\ ${ }^{b}$ Faculdade de Química, Pontifícia Universidade Católica do Rio Grande do Sul, Av. Ipiranga, 6680, \\ 90619-900 Porto Alegre - RS, Brazil
}

\begin{abstract}
Um sistema catalítico simples e eficiente, baseado em $\mathrm{RuCl}_{3}$ imobilizado em líquidos iônicos, foi desenvolvido para oxidar álcoois a aldeídos e cetonas sob condições brandas. Um novo líquido iônico fluorado, pentadecafluorooctanoato de 1- $n$-butil-3-metilimidazólio, foi sintetizado e demonstrou melhor desempenho que os demais líquidos iônicos empregados. Além disso, este sistema catalítico utiliza oxigênio molecular como agente oxidante, produzindo somente água como subproduto.
\end{abstract}

An efficient and simple catalytic system based on $\mathrm{RuCl}_{3}$ dissolved in ionic liquids has been developed for the oxidation of alcohols into aldehydes and ketones under mild conditions. A new fluorinated ionic liquid, 1-n-butyl-3-methylimidazolium pentadecafluorooctanoate, was synthesized and demonstrated better performance that the other ionic liquids employed. Moreover this catalytic system utilizes molecular oxygen as an oxidizing agent, producing water as the only by-product.

Keywords: biphasic oxidation, ionic liquids, alcohols, molecular oxygen, ruthenium catalysts

\section{Introduction}

One of the urgent issues for chemical industries in the twenty-first century is the search for 'clean' or 'green' technologies. ${ }^{1}$ Two-phase catalysis represents one of the most important alternatives for the design, development, and implementation of green chemistry. ${ }^{2}$ Among the various 'mobile' phases that have been used for the immobilization of transition-metal catalyst precursors, ionic liquids (molten salts) are attracting continuous and increasing interest. ${ }^{3,4}$ The advent of the air and water stable, 1-n-butyl-3-methylimidazolium tetrafluoroborate $\left(\mathrm{BMI}_{\mathrm{BF}}\right)$ and its analog hexafluorophosphate $\left(\mathrm{BMI}_{\mathrm{PF}}{ }_{6}\right),{ }^{5}$ which possesses a wide range of liquid phase, negligible vapour pressure, low viscosity, high thermal and chemical stability as well as a wide electrochemical window (up to $7 \mathrm{~V}$ ), ${ }^{6}$ enables reactions to be performed ranging from DielsAlder type processes to hydroformylations in biphasic conditions..$^{7-10}$ In these biphasic systems the products are easily separated from the reaction mixture by simple decantation or distillation and the recovered catalyst

*e-mail: jdullius@pucrs.br solution can be reused several times without any significant changes in its catalytic performance. The greatest advantage of the biphasic catalysis in ionic liquids is that it allows, in many cases, the direct transposition of known homogeneous one-phase reactions to two-phase systems without the synthesis of specially tailored ligands and/or complexes.

The oxidation of alcohols into aldehydes and ketones is a fundamental reaction in organic synthesis, and numerous oxidizing agents are available to influence this key reaction. ${ }^{11}$ However, these reagents are usually toxic and their use induces hazardous problems. ${ }^{12}$

From an economical and environmental point of view, the development of catalytic processes using aerobic conditions is of great value. ${ }^{13}$ This oxidant is atom efficient $^{14}$ and water is its only by-product.

While we were investigating the direct transposition of homogeneous oxidation reactions ${ }^{15-24}$ to a biphase conditions, ${ }^{25-27}$ we also observed that $\mathrm{RuCl}_{3}$ dissolved in 1-n-butyl-3-methylimidazolium tetrafluoroborate $\left(\mathrm{BMI}_{\mathrm{BF}}\right)$ in the presence of molecular oxygen can oxidize hydroxyl groups to carbonyl functions. Moreover, we have shown that the ionic liquid medium has a beneficial effect on these ruthenium catalytic systems compared to those performed using organic solvents. 


\section{Experimental}

\section{General}

All chemicals acquired from commercial sources were utilized without any further purification. The ionic liquids $\left(\mathrm{BMI} . \mathrm{BF}_{4}\right),{ }^{28}\left(\mathrm{BMI} \mathrm{PF}_{6}\right)^{28}$ and $\left(\mathrm{BMI} . \mathrm{OOCCF}_{3}\right)^{29}$ were prepared according to literature. The catalytic oxidation was performed in a $100 \mathrm{~mL}$ stainless steel autoclave, equipped with a magnetic bar, temperature indicator and a manometer. The catalytic reaction products were analyzed by gas chromatography on an Varian 3400 CX chromatograph with FID detector, equipped with a polydimethylsiloxane column $30 \mathrm{~m}, 0.25 \mathrm{~mm}$ id and film thickness of $0.2 \mu \mathrm{m}$, working between 50 and $200{ }^{\circ} \mathrm{C}$ with

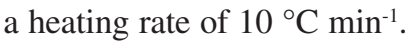

Preparation of 1-n-butyl-3-methylimidazolium pentadecafluorooctanoate (BMI.COO $\left.\left(\mathrm{CF}_{2}\right)_{6} \mathrm{CF}_{3}\right)$

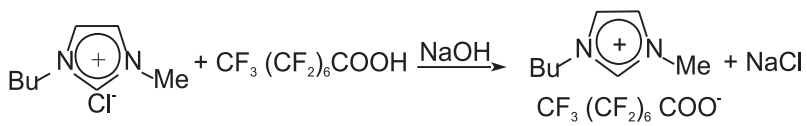

Sodium hydroxide (1.173 mg, $29.32 \mathrm{mmol})$ dissolved in water $(10 \mathrm{~mL})$ was added to the mixture of 1 - $n$-butyl-3methylimidazolium chloride $(5.116 \mathrm{mg}, 29.32 \mathrm{mmol})$ and pentadecafluorooctanoic acid (12.139 mg, $29.32 \mathrm{mmol})$ in water $(30 \mathrm{~mL})$, at room temperature. After stirring for $1 \mathrm{~h}$, the reaction mixture was dried in a vacuum. After drying the mixture, dichlorometane $(100 \mathrm{~mL})$ was added. It was then filtered through a column of celite $(l=3 \mathrm{~cm})$ and all volatiles were removed under reduced pressure $(15.375$ mg, 95\%).

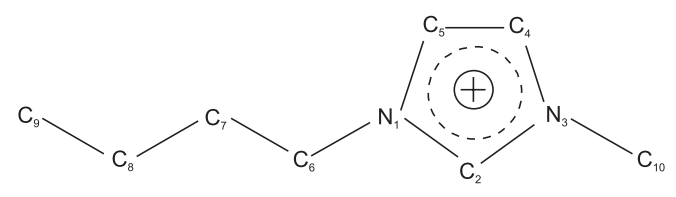

IR (film) $v_{\max } / \mathrm{cm}^{-1}: 3142$ and $3052 v(\mathrm{C}-\mathrm{H})$ aromatic; 2967 and $2878 v(\mathrm{C}-\mathrm{H})$ aliphatic; 1242, 1203 and 1145 $[v(\mathrm{C}-\mathrm{F})] ; 1571$ and $1467 v(\mathrm{C}=\mathrm{C}) ; 1686 v(\mathrm{C}=\mathrm{O})$ carboxilic acid.

${ }^{1} \mathrm{H}$ NMR (ppm): $\delta$ 9.92, s, $1 \mathrm{H}, \mathrm{H}(2) ; 7.97, \mathrm{~s}, 1 \mathrm{H}, \mathrm{H}(4)$; 7.89, s, 1H, H(5); 4.40, t, 2H, H(6); 4.08, s, 3H, H(10); 1.91 and $1.35,2 \mathrm{~m}, 4 \mathrm{H}, \mathrm{H}(7)$ and $\mathrm{H}(8) ; 0.94, \mathrm{t}, 3 \mathrm{H}, \mathrm{H}(9)$.

${ }^{13} \mathrm{C}$ NMR (ppm): $\delta 138.1 \mathrm{C}(2) ; 124.0 \mathrm{C}(4) ; 122.8 \mathrm{C}(5)$; 49.2 C(6); 35.6 C(10); 32.2 C(7); $19.2 \mathrm{C}(8) ; 12.9 \mathrm{C}(9)$; $205.9 \mathrm{C}(11)$.

${ }^{19} \mathrm{~F}$ NMR (ppm): $\delta-81.3 \mathrm{CF}_{3} ;-116.9 \mathrm{CF}_{2} ;-122.2$, $-122.6,-122.8$ and $-123.3\left(\mathrm{CF}_{2}\right)_{4} ;-126.7 \mathrm{CF}_{2}$.
Typical procedure for the oxidation reaction

Initial investigations were performed with $\mathrm{RuCl}_{3}$ since this compound is known as a catalyst for the oxidation of alcohols under homogeneous conditions. ${ }^{19-24}$ Note that in these one-phase reactions a second component is usually necessary to create an efficient catalytic system. ${ }^{15-18}$ Thus, $\mathrm{RuCl}_{3}$ dissolved in $\mathrm{BMI} \mathrm{BF}_{4}$ promoted efficiently the oxidation of alcohols to the corresponding aldehydes and ketones, under various reaction conditions.

In a typical experiment, $\mathrm{RuCl}_{3}(0.1 \mathrm{mmol})$ was dissolved in the ionic liquid ( $3 \mathrm{~mL})$. This solution and substrate $(10$ mmol) were introduced into a $100 \mathrm{~mL}$ stainless steel autoclave equipped with magnetic stirring bar. The autoclave was then pressurized with oxygen ( $7 \mathrm{~atm})$ and heated at $100{ }^{\circ} \mathrm{C}$ for $24 \mathrm{~h}$. The autoclave was cooled and degassed.

The procucts were isolated by distillation (water was the sole by-product observed) or extracted with organic solvents. The conversion (based on the starting alcohol) and selectivity into carbonyl compound were determined by gas chromatography. The isolated products were characterized by GC-MS, IR, ${ }^{1} \mathrm{H}$ and ${ }^{13} \mathrm{C}$ NMR and by comparison of their retention times (GC) with those ones of the authentic samples.

\section{Results and Discussions}

Some alcohols were tested, transfering homogeneous reactions, employing $\mathrm{RuCl}_{3}$, in organic solvents to twophase conditions in ionic liquids. ${ }^{19}$

The results in Table 1 show that several different secondary alcohols (entries 1, 2, 3 and 4) have been oxidized to ketones with good conversions in relation to the existent systems. Besides the conversions, a relatively higher selectivity was observed when using the ionic liquid $\left(\mathrm{BMI} . \mathrm{BF}_{4}\right)$. It is interesting to note that under homogeneous conditions the oxidation of cyclohexanol by $\mathrm{RuCl}_{3}$ (1 mol\%), dissolved in toluene at $100{ }^{\circ} \mathrm{C}$ for $95 \mathrm{~h}$, gives cyclohexanone with only $21 \%$ selectivity (at $92 \%$ conversion). ${ }^{19}$ This demonstrates the beneficial effect of the ionic liquid on the performance of this oxidation system (entry 3, 100\% selectivity). Moreover the parameters selectivity and conversion depend of the reaction conditions. For example, in the conditions of 80 ${ }^{\circ} \mathrm{C}, 1 \mathrm{~mol} \% \mathrm{RuCl}_{3}, 1$ atm $\mathrm{O}_{2}$ and $5 \mathrm{~h}$ was not observed oxidation of 1-phenylethanol into acetopheneone. ${ }^{19}$ The change of the reaction conditions, over all the time, leads to $53 \%$ conversion and $100 \%$ selectivity (Table1, entry 4 ).

Table 1 shows that the primary activated alcohols present high conversion. According to the entries 5, 6 and 
Table 1. Influence of the biphasic system in the oxidation of alcohols a

\begin{tabular}{|c|c|c|c|c|c|}
\hline entry & substract & product & $\mathrm{cv}^{\mathrm{b}}(\%)$ & $\operatorname{sel}^{\mathrm{c}}(\%)$ & yield ${ }^{\mathrm{d}}(\%)$ \\
\hline 1 & & & 73 & 95 & 61 \\
\hline 2 & & & 96 & 97 & 59 \\
\hline 3 & & & 82 & 100 & 80 \\
\hline 4 & & & 53 & 100 & 47 \\
\hline 5 & & & 100 & 2 & - \\
\hline $6^{e}$ & & & 76 & 88 & 60 \\
\hline $7^{\mathrm{e}, \mathrm{f}}$ & & & 96 & 100 & 70 \\
\hline 8 & & & 100 & 0 & - \\
\hline 9 & & & 100 & 0 & - \\
\hline 10 & & & 0 & - & - \\
\hline
\end{tabular}

aReaction conditions: $0.3 \mathrm{mmol}$ of $\mathrm{RuCl}_{3}, 3 \mathrm{~mL}$ of $\mathrm{BMI}_{\mathrm{B}} \mathrm{BF}_{4}, 10 \mathrm{mmol}$ of substract, $\mathrm{T}=100^{\circ} \mathrm{C}, \mathrm{P}_{\mathrm{O} 2}=2 \mathrm{~atm}, \mathrm{t}=70 \mathrm{~h}$; ${ }^{\mathrm{b}} \mathrm{cv} .=\mathrm{conversion}$ based on starting hydroxyl substrates; ${ }^{\mathrm{c}} \mathrm{sel} .=$ selectivity in the carbonyl product; ${ }^{\mathrm{d}}$ Yield in separated product; ${ }^{\mathrm{e}} \mathrm{t}=24 \mathrm{~h} ;{ }^{\mathrm{f}}$ solvent $=3 \mathrm{~mL}$ of $\mathrm{BMI} . \mathrm{BF}{ }_{4}+15 \mathrm{~mL}$ of tolueno.

7 , depending on the reaction conditions, the benzylic alcohols may be transformed into aldehydes or benzoic acids with high selectivity. In the reaction conditions of the entry 6 obtain $76 \%$ conversion and $88 \%$ selectivity (TOF $1.06 \mathrm{~h}^{-1}$ ). Theses results are comparable to published by Ishii $(80 \%$ conversion, $99 \%$ selectivity and TOF 0.53 $\left.\mathrm{h}^{-1}\right)$ in homogeneous conditions. ${ }^{23}$

The allylic alcohols did not show selectivity in aldehydes (entries 8 and 9). The oxidation reaction went on until ending in total oxidation. Non-activated primary alcohols such as 1-pentanol failed to react under the reaction conditions investigated (entry 10).
In order to study the influence of reaction parameters on the performance of the system formed by the catalyst $\mathrm{RuCl}_{3}$, dissolved in the ionic liquid BMI.BF 4 , cyclopentanol was used. The results are shown in the Table 2.

The conversion of cyclopentanol to cyclopentanone increases with increasing oxygen pressure (compare entries $12,17,18$ and 19), reaction time (entries 2, 20 and 21) and temperature (see entries 2 and 13-16). The selectivity of the ketone formation was very high except when the oxygen pressure was increased to 10 atm (entry 19) whereby cyclopentene was formed and when the temperature was increased to $125{ }^{\circ} \mathrm{C}$ (entry 16). In this temperature the 
Table 2. Effect of the reaction conditions on the oxidation of cyclopentanol by $\mathrm{RuCl}_{3}$ dissolved in $\mathrm{BMI}_{\mathrm{B}} \mathrm{BF}_{4}(3 \mathrm{~mL})$

\begin{tabular}{|c|c|c|c|c|c|c|c|}
\hline entry & $P_{\mathrm{O}_{2}}{ }^{\mathrm{a}}(\mathrm{atm})$ & $\mathrm{RuCl}_{3}(\mathrm{~mol} \%)$ & $\mathrm{t}(\mathrm{h})$ & $\mathrm{T}\left({ }^{\circ} \mathrm{C}\right)$ & $\mathrm{cv}^{\mathrm{b}}(\%)$ & sel. $^{\mathrm{c}}(\%)$ & yield ${ }^{\mathrm{d}}(\%)$ \\
\hline 11 & 2 & 0 & 70 & 100 & 0 & 0 & 0 \\
\hline 12 & 2 & 1 & 70 & 100 & 35 & 100 & 20 \\
\hline 2 & 2 & 3 & 70 & 100 & 96 & 97 & 59 \\
\hline 13 & 2 & 3 & 70 & 25 & 17 & 100 & 16 \\
\hline 14 & 2 & 3 & 70 & 50 & 34 & 100 & 29 \\
\hline 15 & 2 & 3 & 70 & 75 & 52 & 100 & 52 \\
\hline 16 & 2 & 3 & 70 & 125 & 58 & 83 & 44 \\
\hline 17 & air & 1 & 70 & 100 & 3 & 100 & - \\
\hline 18 & 7 & 1 & 70 & 100 & 100 & 99 & 94 \\
\hline 19 & 10 & 1 & 70 & 100 & 100 & 67 & 69 \\
\hline 20 & 2 & 3 & 24 & 100 & 56 & 100 & 36 \\
\hline 21 & 2 & 3 & 48 & 100 & 66 & 100 & 52 \\
\hline
\end{tabular}

${ }^{a}$ Initial pressure; ${ }^{\mathrm{b}} \mathrm{cv} .=$ conversion based on starting hydroxyl substrates; ${ }^{\mathrm{c}}$ sel.= selectivity in the carbonyl product; ${ }^{\mathrm{d}}$ Isolated yields were from an average of two runs.

selectivity decrease may be associated with the instability of the catalytic system. From Table 2 it can be deduced that the best reaction conditions for the oxidation of cyclopentanol are $1 \mathrm{~mol} \%$ of $\mathrm{Ru}, 100^{\circ} \mathrm{C}$ and 7 atm of oxygen (entry 18).

Due to the selectivity improvement of the reactions

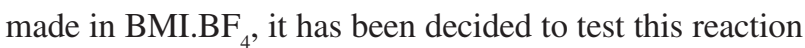
with other ionic liquids (see Table 3).

The new ionic liquid 1-n-butyl-3-methylimidazolium pentadecafluorooctanoate (BMI.COO $\left(\mathrm{CF}_{2}\right)_{6} \mathrm{CF}_{3}$ ) was synthesized to check whether the amount of oxygen dissolved in fluorinated ionic liquids increases as it happens with the fluorinated hydrocarbons, ${ }^{30}$ and enables a higher conversion.

Table 3. Influence of the ionic liquid about the oxidation reaction of cyclopentanol by $\mathrm{RuCl}_{3}{ }^{\mathrm{a}}$

\begin{tabular}{llcccc}
\hline entry & Ionic Liquid & $\begin{array}{c}\mathrm{cv}^{\mathrm{b}} \\
(\%)\end{array}$ & $\begin{array}{c}\text { sel. }^{\mathrm{c}} \\
(\%)\end{array}$ & $\begin{array}{c}\text { Yield }^{\mathrm{d}} \\
(\%)\end{array}$ & $\begin{array}{c}\text { TOF } \\
\left(\mathrm{h}^{-1}\right)\end{array}$ \\
\hline 22 & BMI. BF & 15 & 100 & 15 & 0.63 \\
23 & BMI. PF $_{6}$ & 0 & - & - & - \\
24 & BMI.OOCCF $_{3}$ & 37 & 100 & 37 & 1.54 \\
25 & ${\text { BMI.OOC }\left(\mathrm{CF}_{2}\right)_{6} \mathrm{CF}_{3}}_{26}$ & 35 & 100 & 35 & 1.46 \\
BMI. BF $_{4}+$ sieve $^{\mathrm{e}}$ & 61 & 100 & 60 & 2.54 \\
\hline
\end{tabular}

a Reaction conditions: $0.1 \mathrm{mmol}$ of $\mathrm{RuCl}_{3}, 3 \mathrm{~mL}$ of ionic liquid, 10 mmol de substrate, $\mathrm{T}=100{ }^{\circ} \mathrm{C}, \mathrm{P}_{\mathrm{O} 2}=7 \mathrm{~atm}, \mathrm{t}=24 \mathrm{~h} ;{ }^{\mathrm{b}} \mathrm{cv}$. $=$ conversion based on starting hydroxyl substrates; ${ }^{\mathrm{c}} \mathrm{sel} .=$ selectivity in the carbo-

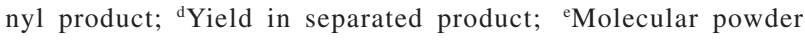
sieve $=100 \mathrm{mg}$.

In Table 3 it can be noticed a significant improvement with the fluorinated liquids (entries 22, 24 and 25). Theses results indicate better performance of the fluorinated liquids (TOF $1.54 \mathrm{~h}^{-1}$, BMI.OOCCF $_{3}$, and $1.46 \mathrm{~h}^{-1}$, BMI.OOC $\left.\left(\mathrm{CF}_{2}\right)_{6} \mathrm{CF}_{3}\right)$ when compared to the other ionic liquids employed (TOF $0.63 \mathrm{~h}^{-1}, \mathrm{BMI} . \mathrm{BF}_{4}$ ) in the reaction conditions investigated.
Notwithstanding, it is important to note that the $\mathrm{BMI}_{\mathrm{BF}}$ and the fluorinated ionic liquid does not decompose apparently during the reaction according to the ${ }^{1} \mathrm{H}$ and ${ }^{13} \mathrm{C}$ NMR analysis of the recovered ionic liquid. However, attempts to perform these oxidation reactions using 1-n-butyl-3-methyl imidazolium hexafluorophosphate $\left({\mathrm{BMI} . P F_{6}}_{6}\right)$ ionic liquid resulted in extended decomposition of the latter (entry 23).

The ionic catalytic solution can be reused maintaining the selectivity in ketone, however, a continuous drop in the conversion had been observed.

Trying to understand the reason of the deactivation molecular powder sieve was added to reaction with $\mathrm{BMI} \mathrm{BF}_{4}$ (entry 26), because this ionic liquid was chosen with standard in the study of reaction conditions. To Schwartz, ${ }^{31}$ water may decrease the activity of the Rucatalytic systems, and to Markó, ${ }^{32}$ the use of molecular powder sieves increases the activity of the reactions.

From this experiment (entry 26), the use of molecular powder sieves in the proposed system, increases significantly the conversion (TOF $2.54 \mathrm{~h}^{-1}$ ), however a continuous drop in the conversion was observed (from $61 \%$ on the first run to $15 \%$ on the fourth run). The nature of this catalyst deactivation is not yet clear and it is under investigation.

\section{Conclusions}

In summary, the advantages of this oxidation system are numerous: (i) transition-metal catalyzed oxidation reactions can be performed in room temperature ionic liquids; (ii) $\mathrm{RuCl}_{3}$ is completely soluble in the ionic liquids tested, giving a homogeneous oxidation solution; (iii) the ionic liquids medium has a beneficial effect on the $\mathrm{RuCl}_{3}$ catalyst performance when the selectivity; (iv) molecular 
oxygen with an oxidizing agent produces water as the only by-product, that is removed by molecular powder sieves; ( $v$ ) this system can be reused; (vi) most rates of oxidation in these systems are at least comparable to previously published data; (vii) the new fluorinated ionic liquid has better performance that the others ionic liquids employees.

\section{Acknowledgments}

We thank FAPERGS for partial financial support and PUCRS (J. E. D.) for scholarships.

\section{References}

1. Baker, R. T.; Tumas, W.; Science 1999, 284, 1427.

2. Anastas, P. T.; Bartlett, L. M.; Kirchhoff, M. M.; Williamson, T. C.; Catal. Today 2000, 55, 11.

3. Dupont, J.; Consorti, C. S.; Spencer, J.; J. Braz. Chem. Soc. 2000, 11, 337.

4. Welton, T.; Chem. Rev. 1999, 99, 2071.

5. Suarez, P. A. Z.; Dullius, J. E. L.; Einloft, S.; de Souza, R. F.; Dupont, J.; Polyhedron 1996, 15, 1217.

6. Dupont, J.; Suarez, P. A. Z.; de Souza, R. F.; Burrow, R. A.; Kintzinger, J. -P.; Chem. Eur. J. 2000, 6, 2377 and references therein.

7. Chauvin, Y.; Mussmann, L.; Olivier, H.; Angew. Chem., Int. Ed. Engl. 1995, 34, 2698.

8. Dullius, J. E. L.; Suarez, P. A. Z.; Einloft, S.; de Souza, R. F.; Fischer, J.; De Cian, A.; Organometallics 1998, 17, 815.

9. Carmichael, A. J.; Earle, M.; Holbrey, J. D.; McCormac, P. B.; Seddon, K. R.; Org. Lett. 1999, 1, 997.

10. de Bellefon, C.; Pollet, E.; Grenouillet, P.; J. Mol. Catal. A: Chem. 1999, 145, 121.

11. Sheldon, R. A.; Kochi, J. K.; Metal-Catalyzed Oxidations of Organic Compounds; Academic Press: New York, 1981; Procter, G. In Comprehensive Organic Synthesis; Ley, S. V., ed.; Pergamon: Oxford, 1991, vol. 7, p 305.

12. Ley, S. V.; Madin, A. In Comprehensive Organic Synthesis; Trost, B. M.; Fleming, I., Ley, S. V.; eds.; Pergamon: Oxford, 1991, vol. 7, p 251.

13. Mukaiyama, T.; Yamada, T.; Bull. Chem. Soc. Jpn. 1995, 68 , 17.
14. Trost, B. M.; Science 1991, 254, 1471.

15. Hudlický, M.; Oxidations in Organic Chemistry; ACS Monograph: Washington, DC, 1990.

16. Procter, G. In Comprehensive Organic Synthesis; Ley, S. V., ed.; Pergamon: Oxford, 1991.

17. Naota, T.; Takaya, H.; Murahashi, S. I.; Chem. Rev. 1998, 98 , 2599.

18. Ley, S. V.; Norman, J.; Griffith, W. P.; Marsden, S. P.; Synthesis 1994, 639.

19. Tang, R.; Diamond, S. E.; Neary, N.; Mares, F.; J. Chem. Soc., Chem. Commun. 1978, 562; Wolfson, A.; Wuyts, S.; De Vos, D. E.; Vankelecom, I. F. J.; Jacobs, P. A.; Tetrahedron Lett. 2002, 43, 8107.

20. Wang, G. Z.; Andreasson, U.; Bäckvall, J. E.; J. Chem. Soc., Chem. Commun. 1994, 1037.

21. Karlsson, U.; Wang, G. Z.; Bäckvall, J. E.; J. Org. Chem. 1994, 59, 1196.

22. Markó, I. E.; Giles, P. R.; Tsukazaki, M.; Brown, S. M.; Urch, C. J.; Science 1996, 274, 2044.

23. Hanyu, A.; Takezawa, E.; Sakaguchi, S.; Ishii, Y.; Tetrahedron Lett. 1998, 39, 5557.

24. Dijksman, A.; Arends, I. W. C. E.; Sheldon, R. A.; Chem. Commun. 1999, 1591.

25. ten Brink, G.-J.; Arends, I. W. C. E.; Sheldon, R. A.; Science 2000, 287, 1636.

26. Klement, I.; Lütjens, H.; Knochel, P.; Angew. Chem., Int. Ed. Engl. 1997, 36, 1454.

27. Matsushita, T.; Ebitani, K.; Kaneda, K.; Chem. Commun. 1999, 265 and references therein.

28. Dupont, J.; de Souza, R. F.; Einloft, S. M. O.; Dullius, J. E. L.; Suarez, P. A. Z.; J. Chim. Phys. 1998, 95, 1626.

29. Dupont, J.; de Souza, R. F.; Suarez, P. A. Z.; Consorti, C. S.; Fulmer, S. L.; Richardson, D. P.; Smith, T. E.; Wolff, S.; Org. Synth. 2002, 79, 236.

30. Sharts, C. M.; Reese, H. R.; J. Fluorine Chem. 1978, 11, 637.

31. Blackburn, T. F.; Schwartz, J.; J. Chem. Soc., Chem. Comm. 1977, 157.

32. Markó, I. E.; Giles, P. R.; Tsukazaki, M.; Regnaut, I. C-; Urch, C. J.; Brown, S. M.; J. Am. Chem. Soc. 1997, 119, 12661.

Received: January 20, 2005

Published on the web: November 24, 2005 